\title{
PENINGKATAN SENSITIVITAS SENSOR KOIL DATAR MEMPERGUNAKAN SOFT MAGNETIC VITROVAC
}

\author{
T. Emrinaldi ${ }^{1}$, Defrianto ${ }^{1}$, S. Fiddunya ${ }^{1}$, A. Wati $^{1}$, R. N. Setiadi ${ }^{1}$, L. Umar ${ }^{1 *}$ \\ ${ }^{1}$ Jurusan Fisika FMIPA Universitas Riau, Indonesia \\ *e-mail: lazuardi.umar@unri.ac.id
}

\begin{abstract}
ABSTRAK
Penelitian ini membahas tentang disain dan pembuatan sensor pengukur ketebalan logam non magnetik berbasis sensor Eddy Current yang berbentuk koil datar. Prinsip yang dipergunakan pada sensor Eddy Current adalah perubahan nilai induktansi mutual koil akibat adanya objek di dalam medan magnetiknya. Koil yang dibuat terdiri atas double layer searah dan berlawanan arah didesain menggunakan Software Corel Draw dicetak pada bahan printed circuit board (PCB) dengan dimensi sebesar $152.4 \mathrm{~mm}$ x $101.6 \mathrm{~mm}$, yang memiliki jarak antar jalur (track) sebesar $0.125 \mathrm{~mm}$. Evaluasi Induktansi Double Layer dilakukan mempergunakan modul L/V Converter EVB-LDC 1000 yang mengubah ketebalan pelat menjadi nilai induktansi. Penambahan lapisan tipis Vitrovac sepanjang $30 \mathrm{~mm}$ yang dipasang searah dengan arah lilitan di dalam inti koil berdiameter $2 \mathrm{~mm}$ telah dilakukan untuk menaikkan nilai sensitivitas sensor yang memberikan kenaikan nilai sensitivitas sebesar $S=0.321 \mathrm{uH} / \mathrm{mm}$ atau sebesar 33.2\%. Koil mampu untuk mengukur ketebalan pelat sampai dengan $10 \mathrm{~mm}$ dengan baik.
\end{abstract}

Kata Kunci: Sensor Eddy Current; Non-Magnetik; EVB LDC 1000; Ketebalan Pelat; Koil Datar

\begin{abstract}
[Title: Increased Sensitivity Of Flat Coil Sensor Using Vitrovac Soft Magnetic] This study reports the design of non-magnetic plate thickness sensors based on Eddy Current principld in the form offlat coils. The principle used in the Eddy Current sensor is a change of mutual coil inductance due to the presence of objects in the magnetic field. The coil is made up of direct and opposite direction double layer coil designed using Corel Draw Software based on printed circuit board (PCB) material with dimensions of $152.4 \mathrm{~mm} \times 101.6$ $\mathrm{mm}$, which has a track distance of $0.125 \mathrm{~mm}$. Double layer coil inductance evaluations are carried out using the EVB LDC $1000 \mathrm{~L} / \mathrm{V}$ Converter module which converts plate thickness into inductance values. The addition of a $30 \mathrm{~mm}$ Vitrovac thin film mounted in the direction of the winding in the $2 \mathrm{~mm}$ diameter coil core has been carried out to increase the sensitivity value of the sensor which gives an increase in sensitivity value of $\mathrm{S}=0.321 \mathrm{uH} / \mathrm{mm}$ or $33.2 \%$. The coil is able to measure plate thickness up to $10 \mathrm{~mm}$ well.
\end{abstract}

Keywords: Eddy Current Sensor; Non-Magnetic; EVB LDC 1000; Plate Thickness; Flat Coil.

\section{PENDAHULUAN}

Pengukuran ketebalan logam sangat diperlukan pada dunia industri seperti logam, otomotif, kemasan dan sebagainya. Untuk itu telah tersedia saat ini berbagai teknologi untuk mendeteksi, misalnya metode uji tidak merusak (non-destructive techniques, NDT) yang banyak dipergunakan dalam industri logam untuk menguji kualitas material dimana tidak memerlukan kontak dengan sampel uji (Martín, 2011). Pengukur ketebalan logam lainnya yang lebih canggih yaitu Ultrasonic Thickness. Alat ini hanya membutuhkan satu sisi dari material dan penerapannya relatif mudah, namun demikian alat ini mempunyai kekurangan yaitu harganya yang cukup mahal dan kurang sesuai untuk pengukuran material yang tipis. Metode lainnya seperti pulsed eddy current banyak dipergunakan untuk aplikasi industri logam (Sophian, 2017).

Sensor induktif yang menggunakan prinsip Eddy Current memiliki banyak kelebihan yang dapat digunakan seperti hasil pengukurannya sangat akurat, memiliki sensitivitas yang tinggi, mampu diujikan pada setiap logam. Untuk mengukur ketebalan, pemeriksaan mutu, penambahan dan perawatan permukaan dalam berbagai aplikasi 
teknologi dapat digunakan metode eddy current. Untuk bahan magnetik dan non-magnetik, pengujian dapat dilakukan dengan metode Eddy current, selain itu juga dipergunakan pada bidang otomotif serta bidang automatisasi baik untuk industri maupun untuk penggunaan sektor pribadi seperti dijelaskan oleh Horsky (2005).

Emrinaldi (2017) telah mengembangkan sensor induktif prinsip eddy current mempergunakan koil spiral berbahan PCB FR4, yang dapat dipergunakan untuk menentukan ketebalan lapisan logam non magnetik seperti tembaga dan alumunium tetapi kurang sensitif. Oleh karena itu, pada penelitian dilakukan bertujuan untuk meningkatkan sensitivitas deteksi dengan mengkarakterisasi koil datar yang ditambahan vitrovac mempergunakan modul LDC 1000 sehingga alat menjadi lebih handal dan mudah dalam mengidentifikasi ketebalan pelat. Aplikasinya sangat diperlukan untuk pengusaha bengkel las, bengkel mobil untuk menentukan ketebalan pelat dasar, pengrajin pembuatan kubah masjid, pengrajin emas dan perak serta pengusaha sepuh (chrom) dan sebagainya yang memerlukan informasi ketebalan pelapisan logam. Alat ini dapat membantu pekerjaan para pengrajin sehingga hasil pengukuran ketebalan akan lebih akurat. Ketelitian dan sensitivitas dari suatu alat ukur sangat dibutuhkan untuk mendapatkan hasil yang mendekati nilai yang sebenarnya.

\section{METODE}

\section{Prinsip Kerja Arus Eddy untuk Mengukur Ketebalan Pelat}

Eddy current dalam kelistrikan disebut juga arus Foucault (Foucault current) yang terjadi jika sebuah konduktor digerakkan memotong medan magnet, yang berarti adanya perubahan medan melingkar konduktor akibat fenomena posisi konduktor berubah relatif terhadap arah medan magnet yang tetap. Prinsip kerja sensor eddy current dapat dilihat pada Gambar 1.

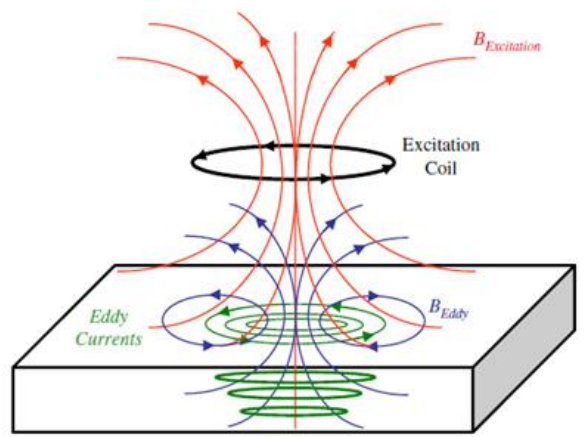

Gambar 1. Skema cara kerja eddy current (Wang, 2015)
Loop tertutup yang terinduksi dalam bidang tegak lurus terhadap fluks magnetic diperlihatkan pada Gambar 1. Arus ini terpusat pada permukaan berdekatan dengan sebuah kumparan eksitasi dan kekuatannya menurun dengan jarak dari kumparan. Sensor induktif dikenal memiliki ketahanan terhadap kondisi lingkungan, salah satu prinsip yang dipakai memanfaatkan sifat arus eddy (eddy current) pada objek ukur, terutama berkaitan dengan material non-feromagnetik. Pengukuran dengan sensor induktif pada penelitian berbentuk planar koil akan menghasilkan medan magnetik bolak balik pada ujung probe (Malik et al, 2015).

Ketika objek (material) pengganggu didekatkan dengan medan magnetik maka medan akan menginduksikan sejumlah kecil arus eddy dalam material. Medan magnetik yang berlawanan dengan medan dihasilkan dari sensor eddy current. Interaksi antara kedua medan magnetik ini akan berubah jika terdapat jarak antara sensor dengan material pengganggu (target). Rangkaian elektronik sensor kemudian mengukur interaksi medan ini dan membangkitkan tegangan keluaran yang proporsional dengan perubahan jarak diantara sensor dengan objek.

Induktansi koil datar berubah karena gangguan dari material konduktif dalam medan magnetic. Pengaruh dari arus bolak balik pada koil menyebabkan terjadi dua jenis induktansi yaitu induktansi diri (self-inductance) dan induktansi bersama (mutual inductance). Medan magnetik interval yang dikenal sebagai induktansi diri dapat dihitung menggunakan Hukum Biot-Savart yang diberikan sebagai berikut.

$$
\varepsilon=-\frac{d \phi_{m}}{d t}=-L \frac{d l}{d t}
$$

\section{Pengukuran Ketebalan Pelat Logam}

Pengukuran ketebalan pelat ini bekerja berdasarkan perubahan induktansi yang dialami flat-coil ketika didekatkan ke material objek dengan ketebalan yang berbeda. Perbedaan ketebalan material objek berpengaruh kepada induktansi mutual antara flat-coil dan material. Fenomena ini terjadi berdasarkan adanya eddy current yang terjadi pada material. Ketika flat-coil yang dieksitasi dengan arus bolak-balik didekatkan pada material nonferromagnetic konduktif, medan magnetik primer akan menembus material dan menghasilkan arus eddy secara kontinu dan melingkar. Arus yang terinduksi yang mengalir pada objek test menghasilkan medan magnetik sekunder yang cenderung berlawanan dengan medan magnetik primer. Sistem flat-coil dapat dianggap sebagai sistem transformator seperti pada Gambar 2. 


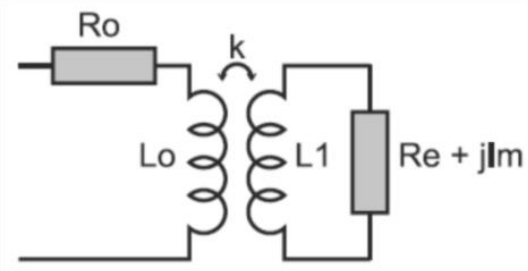

Transformer

Gambar 2. Model sistem flat-coil

Dengan menggunakan hukum Kirchoff, diperoleh dua buah persamaan yaitu:

$$
\begin{aligned}
& R_{0} I+j \omega L_{0} I-j \omega M_{2} I_{e}=V \ldots \ldots . \\
& R_{e} I_{e}+j I_{m} I_{e}+j \omega L_{1} L_{e}-j \omega M_{1} I=0 .
\end{aligned}
$$

dimana $\omega=2 \pi f, \quad R_{0}$ dan $L_{0}$ adalah resistansi dan induktansi flat-coil ketika tidak ada objek test, Re dan L1 adalah resistansi dan induktansi arus eddy, Im adalah induktansi loss, $\mathrm{M} 1=\mathrm{kL} 0$ dan $\mathrm{M} 2=\mathrm{kL} 1$ adalah induktansi mutual antara kedua loop (Javier, 2011). Ketika tidak ada objek test di dekat flat-coil, faktor kopling $\mathrm{k}$ menjadi nol sehingga impedansi, tetapi ketika sebuah objek test didekatkan, impedansi kompleks menjadi $Z_{c}$ seperti pada persamaan (4).

$$
Z_{C}=R_{0}+j \omega L_{0}+\frac{k^{2} L_{0} L_{1} \omega^{2}}{R_{e}+j \omega L_{1}+j I_{m}}
$$

Induktansi dari rangkaian primer ditunjukkan pada persamaan (5).

$$
L_{C}=L_{0}-\frac{(\omega k)^{2} L_{0} L_{1}\left(L_{1}+I_{m} / \omega\right)^{2}}{R_{e}^{2}+\left(\omega L_{1}+j I_{m}\right)}
$$

Arus eddy tidak terdistribusi secara homogen pada volume objek test. Aliran arus lebih besar pada permukaan, menurun secara eksponensial seiring bertambahnya jarak ke permukaan.

Penelitian ini menggunakan metode eksperimen dengan mengukur ketebalan material non magnetik menggunakan prinsip eddy current multi frekuensi. Sensor koil datar (flat koil) merupakan sistem deteksi memanfaatkan arus eddy yang akan dikembangkan dengan multi frekuensi sehingga diperoleh impedansi pengukuran tebal pelat yang berisikan informasi yang diperlukan.

\section{Evaluasi Induktansi Koil dengan EVB- LDC 1000}

Sensor diletakkan di dalam rumahan bertujuan agar sensor kokoh selama pengukuran yang dapat mengeliminir perubahan set up alat. Jarak antara sensor dengan material dibuat konstan yaitu $2 \mathrm{~mm}$ bertujuan untuk menghasilkan pengukuran yang tidak berubah. Rangkaian elektronik dibuat terpisah dari rumahan prototipe yang dapat dilihat pada Gambar 3.

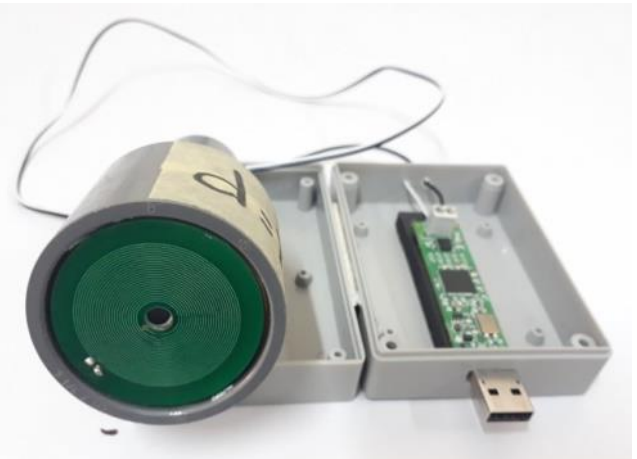

Gambar 3. Prototipe Detektor Eddy Current

Modul yang digunakan dilengkapi dengan perangkat lunak LDC 1000 EVM GUI yang merupakan program untuk menggerakkan segala fungsi dari pengukuran sensor koil datar (Instrument, 2014). Modul evaluation board terhubung ke komputer dengan menggunakan port USB, sehingga data diperoleh dan diolah ke komputer.

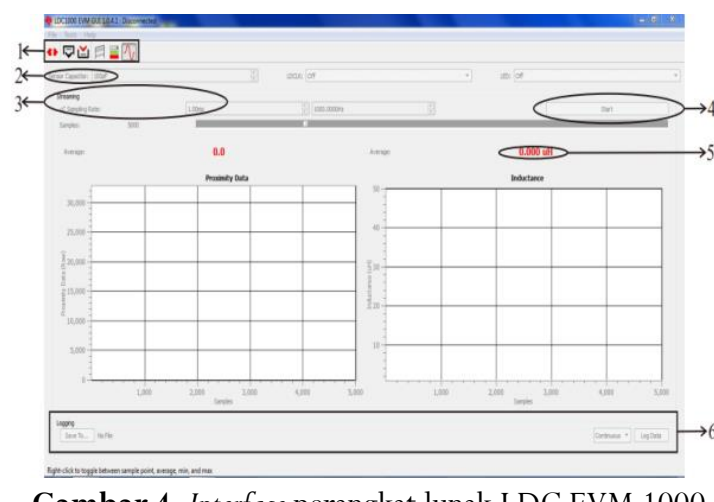

Gambar 4. Interface perangkat lunak LDC EVM 1000

Gambar 4 memperlihankan interface dari perangkat lunak LDC 1000 dengan keterangan 1 (icon toolbar), 2 (set kapasitansi C0), 3 (set waktu), 4 (perintah mulai dan berhenti), 5 (nilai induktasni L) dan 6 (penyimpanan data sampel). Perintah mulai pada perangkat lunak LDC EVM 1000 GUI berfungsi untuk memulai pengukuran dengan meletakkan sensor tanpa menyentuh objek kemudian sensor diletakkan menyentuh objek. Data hasil pengukuran disimpan di dalam database perangkat lunak yang diubah ke dalam format file yaitu csv atau txt kemudian diolah serta dimodelkan menggunakn software sehingga diperoleh grafik hasil pengukuran. 


\section{HASIL DAN PEMBAHASAN}

\section{Bentuk Sensor Koil Datar}

Sensor induktif berupa pelat koil datar yang dikembangkan menggunakan teknologi Printed Circuit Board (PCB) mampu mendeteksi jarak translasi yang sangat kecil bahkan kurang dari orde 0,5 mm. Pembuatan sensor koil datar built in dipesan di perusahaan Spectra Bandung yang mampu membuat $\mathrm{PCB}$ dengan resolusi minimum 10mil $(0.254 \mathrm{~mm})$. Koil double layer searah dan berlawanan arah ditunjukkan oleh Gambar 5a dan $5 b$.

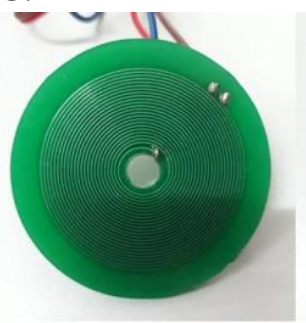

Tampak Depan

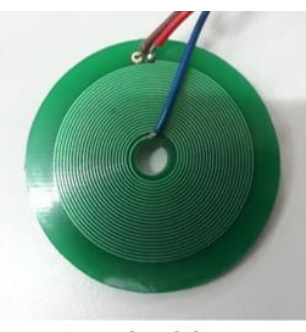

Tampak Belakang
Gambar 5a. Koil double layer searah/clockwise (DL-CW)

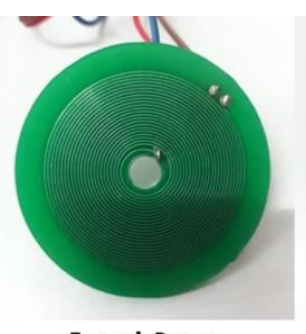

Tampak Depan

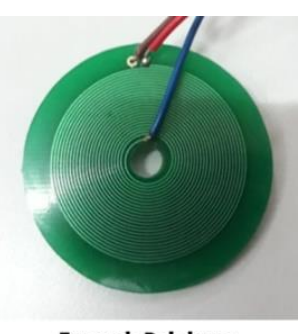

Tampak Belakang
Gambar 5b. Koil double layer berlawanan arah (DL CCW)

Berdasarkan nilai induktansi yang diperoleh koil double layar CW dua kali lebih besar dibandingkan dengan koil single layer, hal ini sesuai dengan teori bahwa penambahan jumlah koil dapat meningkatkan nilai induktansi. Berbeda dengan koil double layer berlawanan arah $(\mathrm{CCW})$, jumlah nilai induktansi yang dihasilkan menjadi nol dikarenakan memiliki induktansi yang sama tetapi arahnya berlawanan. Oleh karna itu, koil double layar searah merupakan koil yang optimal digunakan untuk peningkatan sensitivitas sensor.

\section{Karakterisasi Koil Datar dengan Vitrovac} Peningkatan sensitivitas sensor dilakukan dengan menambahkan material Soft Magnetic dari perusahaan Vitrovac. Bahan soft magnetic ini merupakan bahan amorphous metals yang homogen dan memiliki struktur isotropic yang cocok sebagai bahan soft magnetic, berfungsi untuk menaikkan nilai induktansi koil dan menambah fluks magnetik dalam mendeteksi kedalaman arus eddy pada logam non magnetik. Gambar 6 memperlihatkan pemasangan lembaran tipis Vitrovac pada inti dari koil datar.

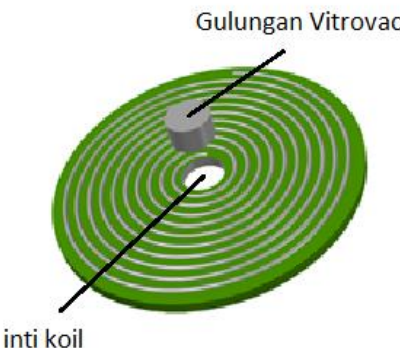

Gambar 6. Gulungan Vitrovac pada inti koil datar

Pengukuran induktansi setiap koil ini dilakukan menggunakan alat Texas Instrument LDC1000 EVM. Rangkaian Coil Evaluation Inductance Inductive LDC1000 Measurement Sensing Sensor SPI TI ini memiliki frekuensi osilasi antara $5 \mathrm{kHz}$ to $5 \mathrm{MHz}$ dengan besar kapasitansi tangki $\mathrm{C}=100 \mathrm{pF}$. Oleh karena kapasitansi yang diatur relative kecil $(\mathrm{C}=5 \mathrm{pF})$ maka nilai arus Eddy yang berubah akibat adanya logam bervariasi ketebalan. Alat NI LDC1000 EVM dihubungkan ke perangkat komputer dengan software produk yang sudah di install pada computer dengan nama LDC1000 EVM GUI 1.0.4.1. Pada software tersebut diberikan input parameter pada alat seperti, sensor capacitor $=5 \mathrm{pF}$ dan $\mathrm{uC}$ sampling rate $=1 \mathrm{~s}$. Lapisan tipis Vitrovac sepanjang $30 \mathrm{~mm}$ dipotong dan dipasang searah dengan arah lilitan dan ditempel pada bagian dalam lobang daripada inti koil berdiameter $2 \mathrm{~mm}$.

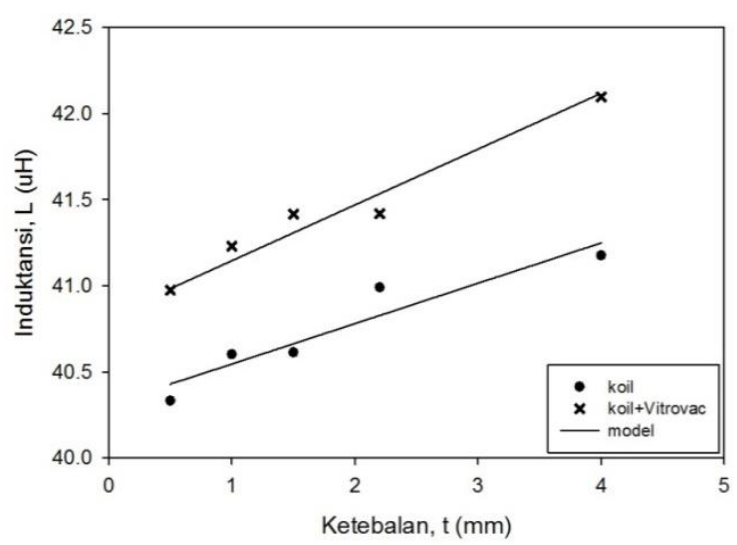

Gambar 7. Pengukuran Induktansu koil datar yang dipasang inti Vitrovac dengan variasi ketebalan pelat

Gambar 7 menunjukkan hasil pengkuran koil polos (tanpa vitrovac) dank oil dengan vitrovac. Perbedaan yang signifikan antara sensor koil datar polos dan dengan sensor yang diberi Vitrovac sebesar $1 \mathrm{mH}$ dan terjadi kenaikan nilai sensitivitas sensor. Kenaikan ini memperlihatkan kecenderungan linier sepanjang pengukuran ketebalan sampai dengan $4 \mathrm{~mm}$. Pada koil polos memberikan nilai sensitivitas 
$\mathrm{S}=0.241 \mathrm{uH} / \mathrm{mm}$ dan koil dengan vitrovac sebesar $\mathrm{S}=0.321 \mathrm{uH} / \mathrm{mm}$ dimana terjadi peningkatan sensitivitas mempergunakan Vitrovac sebesar $33.2 \%$.

\section{KESIMPULAN DAN SARAN}

Pengukuran ketebalan pelat dengan penambahan vitrovac menggunakan modul EVB LDC 1000 memberikan hasil pengukuran yang presisi dan sensitivitas yang tinggi. Koil polos memberikan nilai sensitivitas $\mathrm{S}=0.241 \mathrm{uH} / \mathrm{mm}$ dan koil dengan Vitrovac sebesar $\mathrm{S}=0.321 \mathrm{uH} / \mathrm{mm}$ dimana terjadi peningkatan sensitivitas mempergunakan Vitrovac sebesar 33.2\%.

\section{DAFTAR PUSTAKA}

Martín J.G., Gómez-Gil J. dan Sánchez E.V., 2011, Non-Destructive Techniques Based on Eddy current Testing, Sensors, 11, pp. 25252565.

Sophian A., Tian G., Fan M., 2017, Pulsed Eddy current Non-destructive Testing and Evaluation: A Review, Chin. J. Mech. Eng. 30, pp.500-514.

Horsky, P., 2005, LC Oscillator Driver for Safety Critical Applications.Proc.of DATE 05 Conference, Designers Forum, Munich, Germany, pp. 34-38.
Lazuardi U., 1999, Studi Awal Sensor Getaran Berdasarkan Prinsip Induktif, Thesis S2, Jurusan Fisika FMIPA itb Bandung.

Emrinaldi T., Salomo S., H. Yanuar, Iwantono, Lazuardi U., 2017, Eddy current Sensor Berbasis Flat Coil FR4 Untuk Menentukan Ketebalan Pelat Logam Non Magnetik Al, Spektra: Jurnal Fisika dan Aplikasinya, Volume 2 No. 3.

Wang H. Li W., dan Feng Z., 2015, Noncontact Thickness Measurement of Metal Films Using Eddy-Current Sensors Immune to Distance Variation, IEEE Transactions on instrumentation and measurement, vol. 64, no. 9, pp. 2557.

Malik U. Lazuardi U., dan Yanuar H., 2015, Sensor Planar Induktif Berbasis Bahan PCB FR-4 Untuk Pengukuran Jarak Kecil. Prosiding Seminar Nasional Fisika Universitas Andalas (SNFUA).

Lazuardi, 1999. Studi Awal Sensor Getaran Berdasarkan Prinsip Induktif, Thesis S2, Jurusan Fisika FMIPA ITB Bandung.

Javier G., 2011, Non-Destructive Techniques Based on Eddy current Testing, Sensors, 11, 2525 2565. 